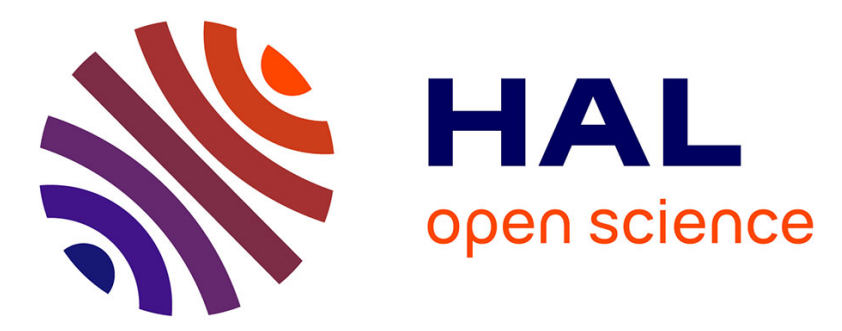

\title{
Behavior of beam web panel under opposite patch loading
}

Omar Mezghanni, Julien Averseng, Abdelhamid Bouchaïr, Hichem Smaoui

\section{To cite this version:}

Omar Mezghanni, Julien Averseng, Abdelhamid Bouchaïr, Hichem Smaoui. Behavior of beam web panel under opposite patch loading. Journal of Constructional Steel Research, 2013, 83, pp.51-61. 10.1016/j.jcsr.2012.12.018 . hal-00856019

\section{HAL Id: hal-00856019 \\ https://hal.science/hal-00856019}

Submitted on 21 Oct 2016

HAL is a multi-disciplinary open access archive for the deposit and dissemination of scientific research documents, whether they are published or not. The documents may come from teaching and research institutions in France or abroad, or from public or private research centers.
L'archive ouverte pluridisciplinaire HAL, est destinée au dépôt et à la diffusion de documents scientifiques de niveau recherche, publiés ou non, émanant des établissements d'enseignement et de recherche français ou étrangers, des laboratoires publics ou privés.

\section{(ㅇ)(1) $\$$}

Distributed under a Creative Commons Attribution - NonCommercial - NoDerivatives 44.0 


\title{
Behavior of beam web panel under opposite patch loading
}

\author{
O. Mezghanni a,b,d,*, J. Averseng ${ }^{c}$, A. Bouchaïr ${ }^{\text {a,b }}$, H. Smaoui ${ }^{\text {d,e }}$ \\ a Clermont Université, Université Blaise Pascal, Institut Pascal, BP 10448, F-63000 Clermont-Ferrand, France \\ b CNRS, UMR 6602, Institut Pascal, F-63171 Aubière, France \\ c LMGC, Université Montpellier 2, CC 048, place Eugène Bataillon, 34790 Montpellier, France \\ d Université de Tunis El Manar, Ecole Nationale d'Ingénieurs de Tunis, LR11ES16, LMOED, 1002, Tunis, Tunisia \\ e Salman Ibn Abdulaziz University, College of Engineering, Saudi Arabia
}

\begin{abstract}
Elastic buckling is studied for a panel with various boundary conditions including simple supports, fixed supports and elastic restraints. The panel is subjected to opposite patch loading. Following a review of existing work on the effects of localized compression, also known as patch loading, a study is conducted to take into account the restraints provided by the flanges of the I beam in a realistic manner. This study is based on a finite element model implemented in the CAST3M software. A new equation is proposed to calculate the buckling critical coefficient for a beam web panel considering the rotational stiffness provided by the flanges. The model is then applied to longitudinally stiffened web panels which are subjected to opposite patch loading. A parametric analysis is performed to determine the transition from a global buckling mode to a local buckling mode where the sub-panels on each side of the stiffener behave separately. The numerical results show that the flexural rigidity of the stiffener is the appropriate parameter that governs the buckling mode. From these results, a formula is proposed to calculate the buckling critical coefficient of stiffened web panels.
\end{abstract}

Keywords

Elastic buckling; Opposite patch loading; Finite element model; Buckling critical coefficient; Flexural rigidity

\section{Introduction}

In steel structures, the connections represent critical points in the structure because of their mechanical and geometrical discontinuities. Fig. 1 shows the distribution of internal forces in a beam-to-column connection which is subject to bending with a double sided configuration. The internal tensile forces transmitted by the bolt rows (N1 to N4), are balanced by a compression force $\mathrm{F}_{\mathrm{c}}$. The web panel loaded in

* Corresponding author at: Université de Tunis El Manar, Ecole Nationale d'Ingénieurs de Tunis, LR11ES16, LMOED, 1002 , Tunis, Tunisia. Tel.: +216 25 807 531.

E-mail addresses: omar.mezghanninr@laposte.net (O. Mezghanni),

julien.averseng@univ-montp2.fr (J. Averseng),

Abdelhamid.bouchair@univ-bpclermont.fr (A. Bouchaïr)

hichem.smaoui@enit.rnu.tn (H. Smaoui). 


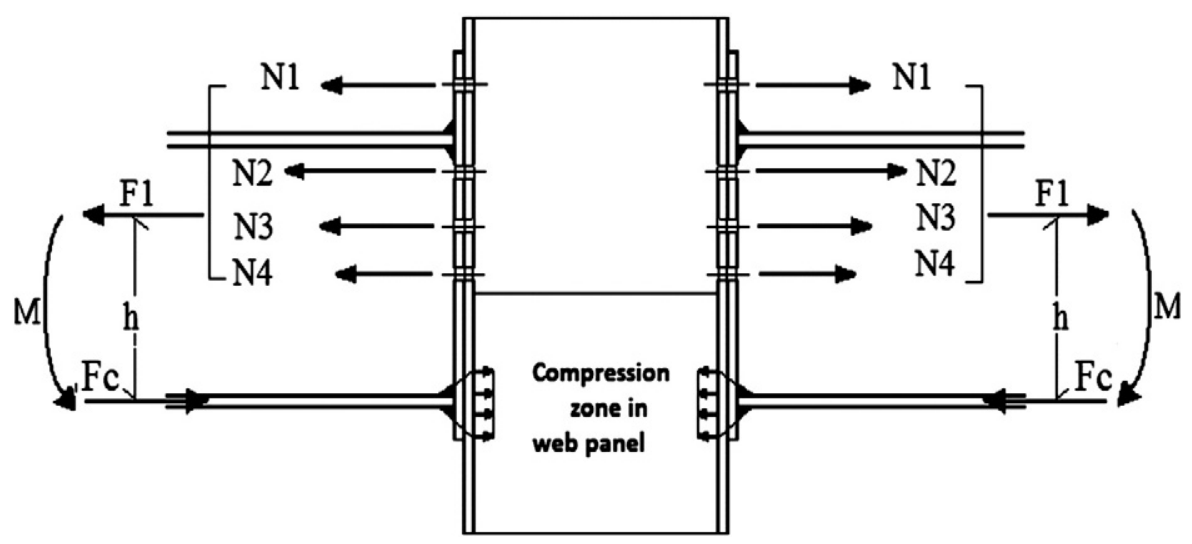

Fig 1. Distribution of internal forces in beam-to-column joint.

compression is more or less restrained by the beam flanges surrounding it. In large size joints, connecting elements of welded plate girders, this zone of web, generally with a high aspect ratio, may develop elastic or elastic-plastic instabilities under compression. This zone can be modeled as a perfect plate that is subject to boundary conditions and loading that represent the joint in a realistic way.

To assess the analytical formulae available in the literature and determine their domain of validity a numerical model is developed by using the finite element software CAST3M [1]. These numerical models are built first for "idealized" plates with an available analytical solution. Then, the models are extended to the case of a steel I beam with the web loaded in its plane. It should be noted that the boundary conditions created by the flanges in the real joint are described by elastic restraints on the web plate edges. Thus, the study is concerned with the elastic instabilities of plates and web panels of steel I beams. It can be considered as a first step covering the case of joint panels with high slenderness that have a dominant behavior in elastic buckling. Actually, in the approaches of EN1993-1-5 [16], whether dominated by a plastic yield mechanism or local elastic buckling the strength of the web panel with or without stiffeners is governed by the dimensionless slenderness ratio $\bar{\lambda}$ that takes as an input parameter the elastic critical load. The present work provides the elastic critical load for panels under elastic restraints, with or without stiffeners. Thus, the determination of the critical elastic load can be considered as a preliminary to the plastic analysis.

\section{Web panel under opposite patch loading}

Several studies proposed analytical models to calculate the elastic critical load of compressed panels with various boundary conditions and loadings. This concerns the web panels of beams or columns loaded in transverse compression where the panel can generally be assimilated to a perfect plate (Fig. 2). Among the available models, those based on the theoretical studies of Sommerfield [2] and Timoshenko [3] are common. They employ an energy approach to determine the elastic critical load of a plate loaded in double compression by two concentrated forces applied in the middle of two opposite edges. Timoshenko and Gere considered two boundary conditions: simple supports on the four edges or two clamped at the loaded edges and the other two simply supported.

The elastic buckling force $\mathrm{F}_{\mathrm{cr}}$ of a rectangular plate was proposed by Timoshenko and Gere [4] under the general form of Eq. (1).

$\mathrm{F}_{\mathrm{cr}}=\mathrm{k}_{\mathrm{cr}} \frac{\pi^{2} \mathrm{E} \mathrm{t}_{\mathrm{W}}^{3}}{12\left(1-\mathrm{v}^{2}\right) \mathrm{h}_{\mathrm{w}}}$

In this general equation, $\mathrm{k}_{\mathrm{cr}}$ represents the elastic buckling coefficient of the plate. It includes the geometrical parameters, the restraint boundary conditions and the load conditions. The parameters $h_{w}, t_{w}$, $\mathrm{E}$ and $v$ are the height and the thickness of the plate, the modulus of elasticity and the Poisson's ratio of the material, respectively. Given the influence of the geometrical characteristics and the boundary conditions on the elastic buckling coefficient $\mathrm{k}_{\mathrm{cr}}$ and as a consequence on the critical load $\mathrm{F}_{\mathrm{cr}}$, this study is concerned with the coefficient $\mathrm{k}_{\mathrm{cr}}$ to determine the critical load of a perfect plate. According to Timoshenko, for a rectangular plate $\left(\mathrm{a}>>\mathrm{h}_{\mathrm{w}}\right)$ loaded in double compression by two equal concentrated forces applied at the middle of two opposite sides, the buckling coefficient $\mathrm{k}_{\mathrm{cr}}$ is equal to $4 / \pi$ for the case of a plate that is simply supported on its four edges and $8 / \pi$ for the plate with the two loaded opposite sides clamped and the two others simply supported.

Other investigations, performed mainly by Legget [5], showed that the solution given by Timoshenko [3] may lead to considerable errors in certain cases. Thus, he proposed another approach based on the representation of the concentrated load by a Fourier series. This led to values of buckling coefficients with reasonable accuracy. Yamaki [6] developed this energetic method to obtain solutions of buckling coefficients with improved accuracy.

Leissa and Ayoub [7] and Deolasi and Datta [8] used the finite element method to model a simply supported plate and calculate its buckling critical load for various aspect ratios. Deolasi and Datta established a comparison between buckling critical loads which were obtained by using the finite element model and those given by Yamaki.

Khan and Walker [9] studied the configuration of a simply supported plate studied by Timoshenko but considering a distributed load applied over a finite length (Fig. 2). They proposed a diagram to calculate the

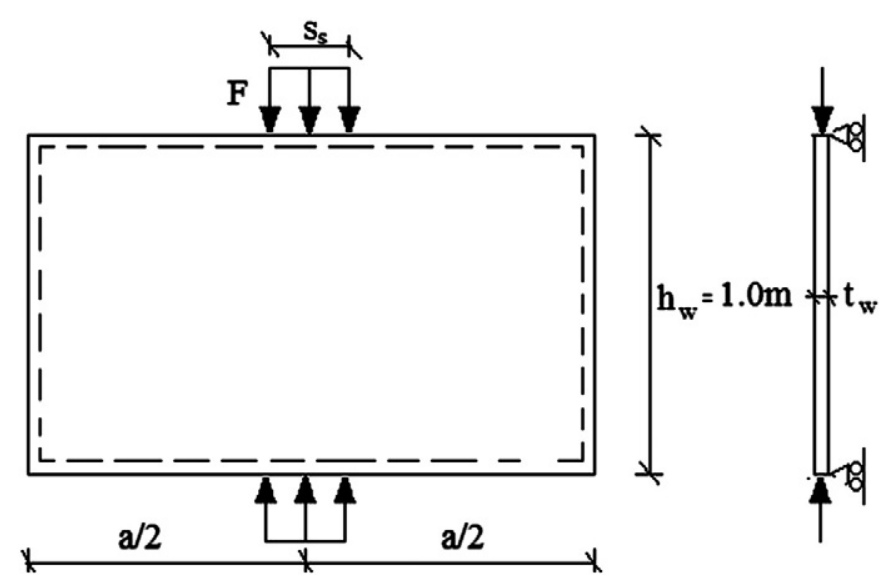

Fig. 2. A simply supported plate subjected to opposite patch loading. 
buckling critical loads for various aspect ratios $\mathrm{a} / \mathrm{h}_{\mathrm{w}}$ and loading length ratios $\mathrm{s}_{\mathrm{s}} / \mathrm{h}_{\mathrm{w}}$. Furthermore, Protte [10] used an energy approach to determine the buckling critical load for different values of $a / h_{w}$ and $s_{s} / h_{w}$, showing an agreement with the results presented by Khan and Walker and Legget. Finally, the same problem was approached by Lagerqvist [11] using a numerical model. He established a series of results for the buckling coefficient considering different ratios $\mathrm{s}_{\mathrm{s}} / \mathrm{h}_{\mathrm{w}}$ ranging from 0 to 0.6 and with $\mathrm{a} / \mathrm{h}_{\mathrm{w}}=1,2$ and $4, \mathrm{t}_{\mathrm{w}}=4 \mathrm{~mm}$ and $\mathrm{h}_{\mathrm{w}}=1000 \mathrm{~mm}$.

To highlight the rotational restraint made by the flanges on the web panel of the beam, Alfutov [12] and Khan and Johns [13] studied the buckling behavior of a plate with elastic rotational restraint and a local load on one edge by using energy methods. They considered that the applied load is balanced by a parabolic tangential stress distribution in the edges of the plate perpendicular to the direction of loading. By using the same stress distribution and a displacement field of sinusoidal type, Robert and Shahabian [14] presented solutions for the buckling coefficient of the beam web panel based on a Galerkin discretization method. Finally, Lagerqvist [11] and Ren and Tong [15] studied the case of a beam web panel under patch loading to obtain the critical load by using finite element modeling.

Furthermore, Lagerqvist [11] studied the influence of the flanges on the critical load of the web panel which is subject to opposite patch loading (Fig. 3). In the model, the load was applied along a length $s_{s}$ in the plane of the web and the loaded nodes were free to move only in the direction of the applied load, labeled 2 in Fig. 3. At the end sections of the beam, in both the flanges and the web, the displacements in the direction of the load (direction 2) and in the out of plane direction (direction 1) and the rotation around the longitudinal axis (6th degree of freedom) were restrained. A parametric study was performed with respect to three parameters: $\beta, \mathrm{a} / \mathrm{h}_{\mathrm{w}}$ and $\mathrm{s}_{\mathrm{s}} / \mathrm{h}_{\mathrm{w}}$. The coefficient $\beta$ ( $\beta=$ $b_{f} t_{f}^{3} / h_{w} t_{w}^{3}$ ) represented the restraint on the web panel edges due to the rotational stiffness of the flanges. It is interpreted as the ratio between the torsion stiffness of the flanges and the bending stiffness of the web panel. The parameters $a / h_{w}$ and $s_{s} / h_{w}$ represent the aspect ratio and the load length factor. The analysis was performed by varying the three parameters in the following intervals: $\beta=1$ to $128, \mathrm{a} / \mathrm{h}_{\mathrm{w}}=1$ to 4 and $\mathrm{s}_{\mathrm{s}} / \mathrm{h}_{\mathrm{w}}=0$ to 1 . Thus, the loading cases covered the range from a concentrated force to a uniformly distributed load along the whole length of the panel. The numerical results led to Eq. (2) for the buckling coefficient:

$\mathrm{k}_{\mathrm{cr}}=\left(1+\left(\mathrm{s}_{\mathrm{s}} / 2 \mathrm{~h}_{\mathrm{w}}\right)\right)\left(3.4+1.8\left(\mathrm{~h}_{\mathrm{w}} / \mathrm{a}\right)^{2}+0.1 \sqrt[4]{\beta}\right)$
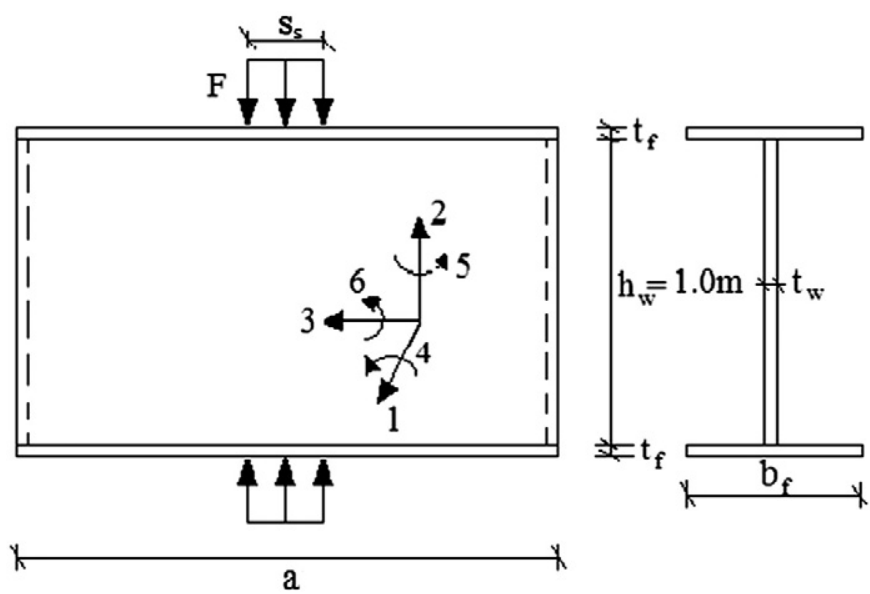

Fig. 3. Model adopted by Lagerqvist (web with flanges).
It may be noted that Eq. (2) proposed by Lagerqvist was adopted in Eurocode 3, part 1.5 [16] in a simplified form. The simplification considers that the influence of the flanges is constant and neglects the influence of the loading length, yielding Eq. (3):

$\mathrm{k}_{\mathrm{cr}}=3.5+2\left(\mathrm{~h}_{\mathrm{w}} / \mathrm{a}\right)^{2}$.

When $\beta$ is small, meaning that the rotational restraint due to the flanges is low, the web panel behaves as a simply supported plate. On the contrary, when $\beta$ becomes high, the web panel behaves as a plate with fully restrained supports. However, Eq. (2) already gives high values of buckling coefficient $k_{\mathrm{cr}}$ when $\beta$ is small, which does not correspond to the behavior of a simply supported plate. Similarly, when $\beta$ increases to infinity, Eq. (2) leads to infinite values which do not reflect the behavior of the plates with fully restrained edges. This observation led us to rely on a numerical model to examine the behavior of a web panel which is subject to opposite patch loading, taking into account the restraint provided by the flanges in a more realistic way. This model will be the reference to assess Eqs. (2) and (3) proposed by Lagerqvist and by the Eurocode 3 .

\section{Influence of the longitudinal stiffening}

In this part, the web panel that was subject to opposite patch loading and was analyzed previously is considered with reinforcement by longitudinal stiffeners (Fig. 4). The addition of a stiffener increases the buckling critical load of the panel for a minor extra cost, through its contribution to the bending deformation in the buckling mode of the stiffened web. This type of stiffener is generally of an open section (plate, L type, ...) or a closed section (U or trapeze,...). The study is limited to the case of a stiffener with an open asymmetric section.

The stiffeners are characterized by the following two dimensionless factors:

- The relative bending stiffness: $\gamma_{s}=\mathrm{EI}_{\mathrm{st}} /\left(\mathrm{h}_{\mathrm{w}} \mathrm{D}\right)$, and

- The relative torsional stiffness: $\Phi_{s}=G K_{s t} /\left(h_{w} D\right)$, where $D=E t_{w}^{3} /$

$\left(12\left(1-v^{2}\right)\right)$ is the bending stiffness of the web panel.

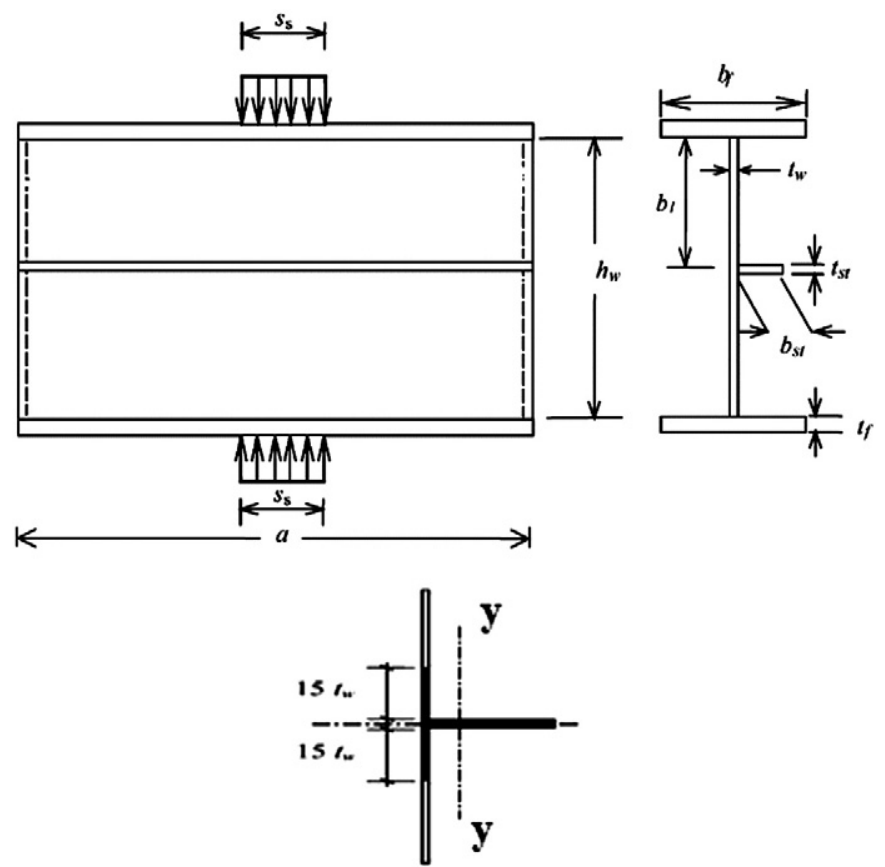

Fig. 4. Longitudinal stiffened web with flanges and the effective cross-section of longitudinal stiffeners according to EN1993-1-5 [14]. 
According to the EN1993-1-5 (6.4) [16], $\mathrm{I}_{\mathrm{st}}$ is the moment of inertia, around the y-axis parallel to the web panel, of a combined section of the stiffener and a part of the web having a width equal to 30 times the thickness of the plate (Fig. 4).

Several studies have been conducted on the case of a web panel that was stiffened longitudinally and was subjected to patch loading but, to our knowledge, no studies have treated the case of opposite patch loading. The former include Graves Smith and Gierlinski [17], Skaloud [18] and Graciano [19]. These authors were primarily concerned with determining the optimal relative rigidity $\gamma^{\mathrm{t}}$ of the stiffener, which is the value, beyond which the stiffener no longer contributes to the panel resistance. In this limit case, the resistance of the panel is controlled by the sub-panels, separated by the stiffener, which behave independently.

Furthermore, they studied the optimum position of the stiffener for which the panel resistance is maximum. The charts of Klöppel, Scheer and Möller [20,21] were established to determine $\gamma^{t}$ for various configurations of loading but not including the case of opposite patch loading. The recommendations of the ECCS [22] do not provide equations for $\gamma^{t}$ for the case of opposite patch loading. In the present study, a finite element model is developed to calculate the buckling coefficient of a web panel that was stiffened longitudinally and was subjected to opposite patch loading. This model also enables us to calculate the optimum stiffness and position of the stiffener for this case.

\section{Numerical modeling of panel buckling}

A numerical model is developed to study the behavior of a simply supported or clamped plate and a web panel which is subject to opposite patch loading. The loading is applied over a limited length along two opposed sides of the plate or the two flanges of the beam in the case of the web panel. The influence of the parameters used by Lagerqvist [11] on the buckling coefficient of the panels is analyzed. These parameters are $a / h_{w}, s_{s} / h_{w}$ and $\beta$. The latter, used for the web panels with flanges, accounts for the rotational restraints due to the flanges. These three parameters are varied in the following intervals: $\beta=1$ to $128, a / h_{w}=1$ to 4 and $s_{s} / h_{w}=0$ to 0.5 .

The numerical approach is based on the calculation of the eigenmodes of elastic instability of the plates by using a finite element software (CAST3M). It makes it possible to obtain directly the buckling critical load of the plates loaded in the opposite patch loading with various boundary conditions ( simply supported or clamped and partially restrained due to the beam flanges). In these models, elastic behavior is assumed, with Young's modulus $\mathrm{E}=210 \mathrm{GPa}$ and Poisson's ratio $\nu=0.3$. Panels are meshed by using triangular thin shell elements (DKT). Each node has six degrees of freedom (numbered 1 to 6) (Fig. 5), and the mesh density is chosen to achieve the convergence of the solution with sufficient accuracy.

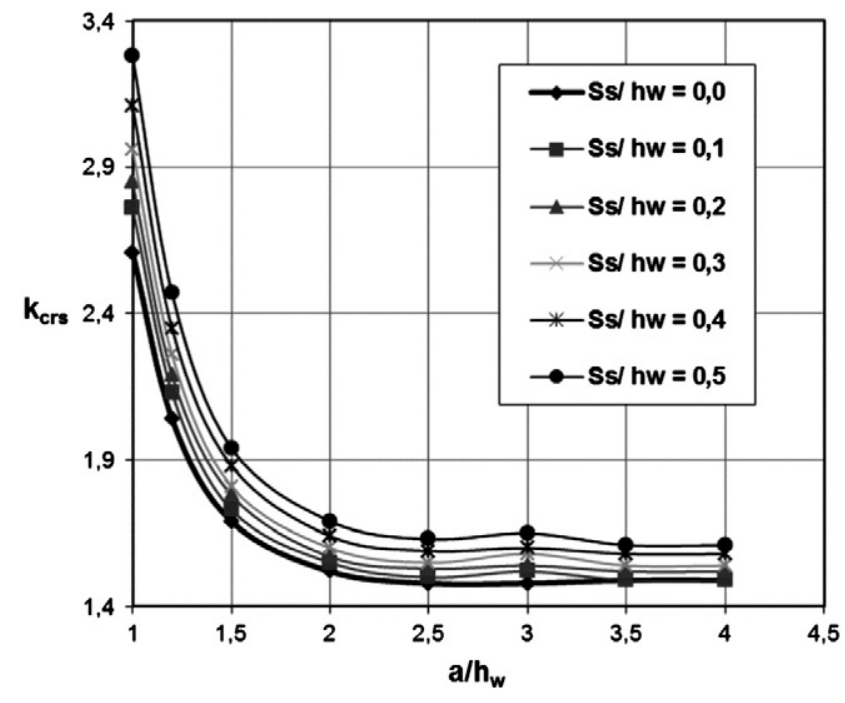

Fig. 6. Elastic buckling coefficient $\mathrm{k}_{\mathrm{crs}}$ of a simply supported plate for different aspect ratios. Effect of the $\left(\mathrm{s}_{\mathrm{s}} / \mathrm{h}_{\mathrm{w}}\right)$ ratio.

\subsection{Plate simply supported on four edges}

In the present paper, the numbers $1,2,3$ and 4, 5, 6 refer to the degrees of freedom in translation in the $\mathrm{x}, \mathrm{y}$ and $\mathrm{z}$ directions and the rotations around the $\mathrm{x}, \mathrm{y}$ and $\mathrm{z}$ axes, respectively (Fig. 3 ).

To validate the model, its results are compared with the existing solutions taken from the literature. For this case, the degree of freedom 1 of the horizontal edges (the loaded ones) is fixed. The degrees of freedom 1, 2 and 6 are fixed in the vertical edges (unloaded) of the plate.

Various calculations are made on rectangular plates having various aspect ratios: $\mathrm{a} / \mathrm{h}_{\mathrm{w}}=1$ to 4 and $\mathrm{s}_{\mathrm{s}} / \mathrm{h}_{\mathrm{w}}=0$ to 0.5 . Fig. 6 shows the evolution of the buckling coefficient $\mathrm{k}_{\mathrm{crs}}$, which was obtained from the results of the numerical model, with respect to the aspect ratio $a / h_{w}$ for various values of the coefficient $\mathrm{s}_{\mathrm{s}} / \mathrm{h}_{\mathrm{w}}$. It can be observed that, for a given loading length, the buckling coefficient decreases for aspect ratios below 2.5, then it exhibits a minor increase that is maximum near 3 and then stabilizes above an aspect ratio of 3.5. For the same aspect ratio $\mathrm{a} / \mathrm{h}_{\mathrm{w}}$, an increase in the loading length gives higher values of the buckling coefficient. The buckling coefficient remains nearly constant for aspect ratios higher than 2.5 .

Table 1 displays the values of the buckling coefficient $\mathrm{k}_{\mathrm{crs}}$ which were obtained from the numerical model developed in the present study and those determined by Legget, Khan, Protte and Lagerqvist. It can be observed that the results of the numerical model are very close to those given by the solutions of these authors. Given that the model

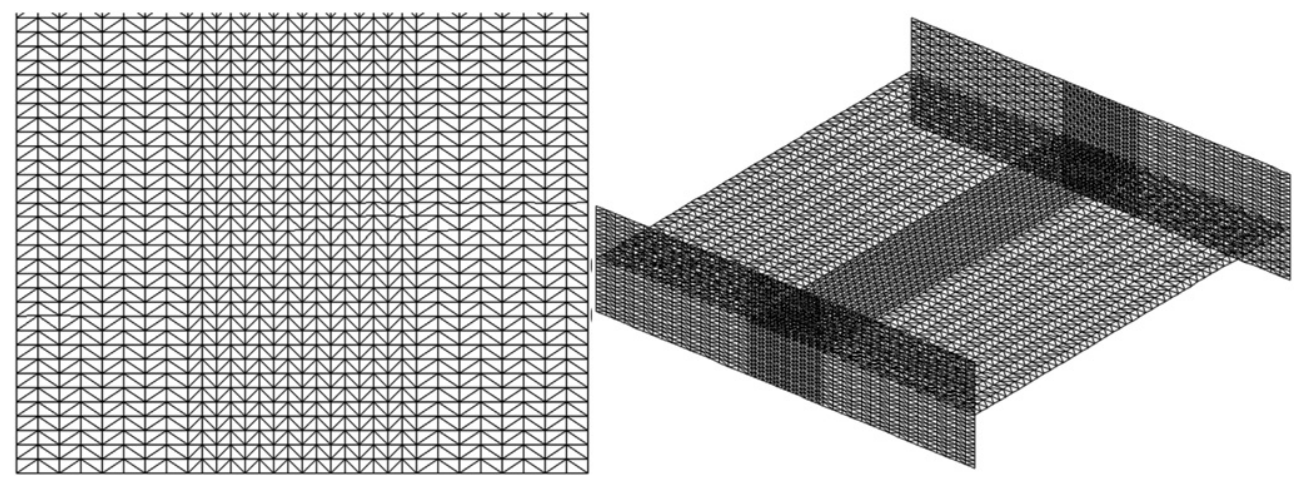

Fig. 5. Finite element mesh used for plates and girder. 
Table 1

Buckling coefficient $\mathrm{k}_{\mathrm{crs}}$ for a simply supported plate.

\begin{tabular}{|c|c|c|c|c|c|c|c|c|c|}
\hline \multirow{2}{*}{$\frac{\mathrm{s}_{\mathrm{s}} / \mathrm{h}_{\mathrm{w}}}{\mathrm{a} / \mathrm{h}_{\mathrm{w}}}$} & \multicolumn{3}{|l|}{0} & \multicolumn{3}{|l|}{0.2} & \multicolumn{3}{|l|}{0.4} \\
\hline & 1 & 2 & 4 & 1 & 2 & 4 & 1 & 2 & 4 \\
\hline Numerical model & 2.61 & 1.52 & 1.49 & 2.74 & 1.54 & 1.49 & 2.98 & 1.61 & 1.55 \\
\hline Legget [5] & 2.46 & 1.51 & 1.46 & - & - & - & - & - & - \\
\hline Khan and Walker [9] & 2.56 & - & - & 2.72 & - & - & 2.88 & - & - \\
\hline Protte [10] & 2.56 & 1.50 & - & 2.64 & - & - & 2.88 & - & - \\
\hline Lagerqvist [11] & 2.47 & 1.51 & 1.46 & 2.55 & - & - & 2.78 & - & - \\
\hline
\end{tabular}

is coherent with the results obtained by these existing formulae, it is used as a basis to establish an equation for the buckling coefficient $\mathrm{k}_{\mathrm{crs}}$ of a simply supported plate which is subjected to opposite patch loading. For that purpose, a parametric study is performed for $\mathrm{a} / \mathrm{h}_{\mathrm{w}}=1$ to 4 and $\mathrm{s}_{\mathrm{s}} / \mathrm{h}_{\mathrm{w}}=0$ to 0.5 . By applying a linear regression to the results of 48 cases, Eq. (4) is obtained.

$\mathrm{k}_{\mathrm{crs}}=1.22+1.33\left(\mathrm{~h}_{\mathrm{w}} / \mathrm{a}\right)^{2}+0.79\left(\mathrm{~s}_{\mathrm{s}} / \mathrm{h}_{\mathrm{w}}\right)^{2}$.

This equation estimates $\mathrm{k}_{\mathrm{crs}}$ with an error less than $5 \%$ in comparison with the results of the numerical model. This constitutes an improvement with respect to the existing equations.

\subsection{Plate with clamped edges}

Boundary conditions with elastic rotational stiffness on the edges of the plate allow the representation of the restraint on the web due to the beam flanges. For an I beam with thick flanges, the rotational stiffness at the web edges is high. This gives a condition of clamped edge to the web-flange connection. However, the vertical edges (the unloaded ones) of the web panel remain simply supported. In the present paper, a plate with these boundary conditions is called clamped plate.

To model these boundary conditions, the degrees of freedom 1 and 6 are blocked for the horizontal edges and 1 and 2 are blocked for the vertical edges of the plate.

The evolution of the buckling coefficient $\mathrm{k}_{\mathrm{crf}}$, given by the numerical model, is shown in Fig. 7 for the studied values of the aspect ratio $\mathrm{a} / \mathrm{h}_{\mathrm{w}}$

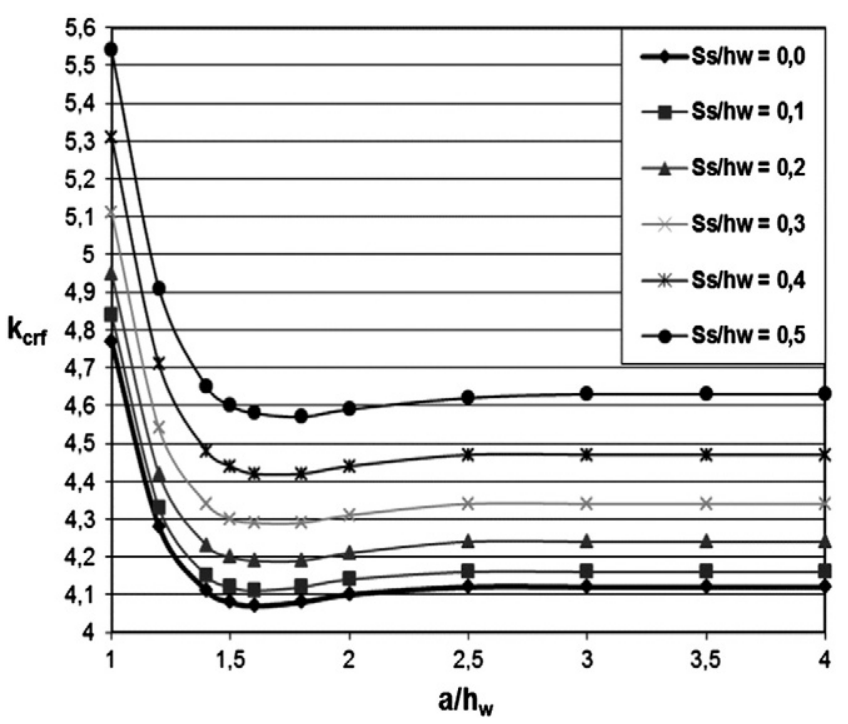

Fig. 7. Elastic buckling coefficient $\mathrm{k}_{\mathrm{crf}}$ of a clamped plate for different aspect ratios. Effect of the $\left(\mathrm{s}_{\mathrm{s}} / \mathrm{h}_{\mathrm{w}}\right)$ ratio. and the loading length ratio $\mathrm{s}_{\mathrm{s}} / \mathrm{h}_{\mathrm{w}}$. As in the case of a simply supported plate, the buckling coefficient increases with the loading length. For a given loading length the buckling coefficient decreases for the low aspect ratios to reach a minimum at the aspect ratios between 1.6 and 1.8 and then it increases to stabilize above an aspect ratio of 3 . For all combinations of parameters $\mathrm{a} / \mathrm{h}_{\mathrm{w}}$ and $\mathrm{s}_{\mathrm{s}} / \mathrm{h}_{\mathrm{w}}$ the buckling coefficient is found to be larger, as expected, for the clamped plate than for the simply supported plate.

For the clamped plate, there is no equation in the literature for the calculation of the buckling coefficient $\mathrm{k}_{\mathrm{crf}}$. By applying a linear regression to the results of 48 cases, (Eq. (5)) is derived for the buckling coefficient of a clamped plate which is subjected to opposite patch loading.

$\mathrm{k}_{\mathrm{crf}}=3.96+0.66\left(\mathrm{~h}_{\mathrm{w}} / \mathrm{a}\right)^{2}+2.13\left(\mathrm{~s}_{\mathrm{s}} / \mathrm{h}_{\mathrm{w}}\right)^{2}$.

The error between the values given by Eq. (5) and the numerical model does not exceed $2 \%$.

\subsection{Web panel of I beam}

This section concerns the behavior of a web panel that is subjected to opposite patch loading and taking into account the elastic restraint due to the flanges. A finite element model is built, similar to Lagerqvist's, except that the displacements and the rotations at the loaded nodes (Fig. 3) are released. The purpose of this change in boundary conditions is to allow finite values of the rotational stiffness due to the flanges. The load is applied to a subset of nodes corresponding to a length $s_{s}$ of the web-flange intersections. The degrees of freedom 1, 2 and 6 of the nodes on the left and the right edges of the flanges and the web are restrained.

\subsubsection{Parametric study}

To analyze and evaluate the influence of various parameters, the evolution of the buckling coefficient $\mathrm{k}_{\mathrm{cr}}$ is determined from the results of the numerical model and Eqs. (2) and (3) proposed by Lagerqvist and the Eurocode 3 part 1.5, respectively. In a preliminary step of the study, the load length factor $\beta$ is varied from 1 to 128 with the values of $\mathrm{a} / \mathrm{h}_{\mathrm{w}}$ and $\mathrm{s}_{\mathrm{s}} / \mathrm{h}_{\mathrm{w}}$ fixed (Fig. 8).

According to these evolutions, with low values of $\beta$, Eq. (2) proposed by Lagerqvist gives higher, i.e., less conservative, values of the buckling coefficient $\mathrm{k}_{\mathrm{cr}}$ than those given by the numerical model. For high values of $\mathrm{k}_{\mathrm{cr}}$ the equation of Lagerqvist is closer to the numerical values but remains non conservative all over the domain of variation of the coefficient $\beta$. As for Eq. (3) proposed by the Eurocode 3, it does not take into account the influence of $\beta$ on the value of $\mathrm{k}_{\mathrm{cr}}$.

It can be observed (Fig. 8) that, as $\beta$ increases, the buckling coefficient becomes higher than that of the simply supported plate and converges towards the case of a plate with clamped edges. The conditions of clamped supports are reached with the flange thickness higher than four times that of the web panel $\left(t_{f} \geq 4 t_{w}\right)$.

Fig. 9 shows the evolutions of the buckling coefficient $k_{\mathrm{cr}}$ with respect to the aspect ratio $a / h_{w}$ for fixed values of $\beta$ and $s_{s} / h_{w}$, which were obtained from the numerical model of the web panel and Eqs. (2) and (3). It can be observed that the values given by the analytical formulae are systematically higher than those given by the numerical model which confirms their non conservative character.

Fig. 10 shows the evolutions of the buckling coefficient $k_{\mathrm{cr}}$ with respect to the factors $s_{s} / h_{w}$ for fixed values of $\beta$ and $h_{w} /$ a. Over the domain of variation of $s_{s} / h_{w}$ and for a low value of $\beta$ (case b) Eqs. (2) and (3) are generally non conservative in comparison with the numerical model. For high values of $\beta$ (case a), these equations produce closer results in comparison with the numerical model.

This parametric study relative to the dominant parameters $\beta, a / h_{w}$ et $\mathrm{s}_{\mathrm{s}} / \mathrm{h}_{\mathrm{w}}$ influencing the buckling coefficient $\mathrm{k}_{\mathrm{cr}}$ shows that Eq. (2) proposed by Lagerqvist is non conservative in comparison with the 


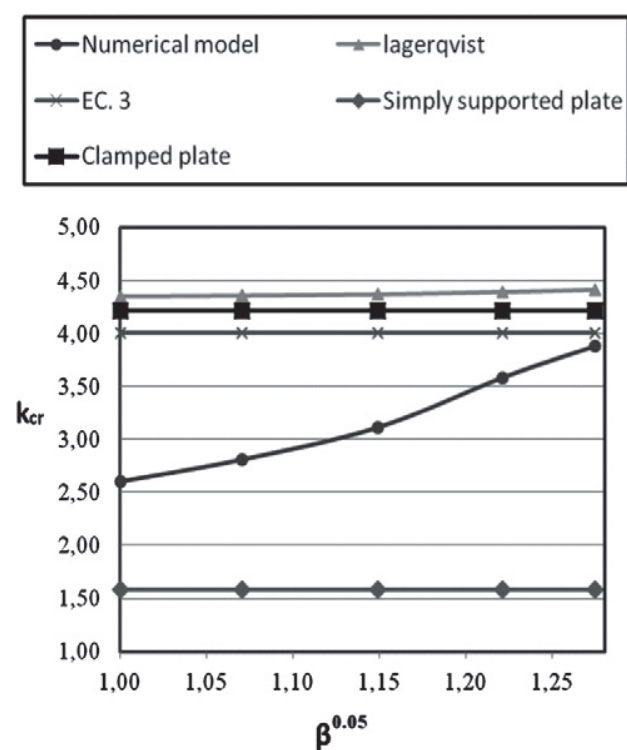

(a) $: \mathrm{s}_{\mathrm{s}} / \mathrm{h}_{\mathrm{w}}=0.2$ and $\mathrm{a} / \mathrm{h}_{\mathrm{w}}=2$

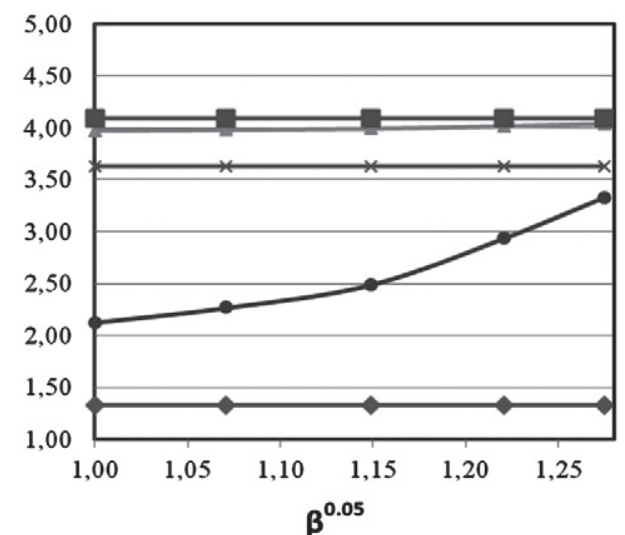

(b) $: \mathrm{s}_{\mathrm{s}} / \mathrm{h}_{\mathrm{w}}=0.2$ and $\mathrm{a} / \mathrm{h}_{\mathrm{w}}=4$

Fig. 8. Buckling coefficient $\mathrm{k}_{\mathrm{cr}}$ versus the coefficient $\beta^{0.05}$.

numerical results taken as a reference. Finally, the Eurocode 3 does not involve the parameters $\beta$ and $s_{s} / h_{w}$ despite their significant influence. This led to the idea of using the results of the numerical model to establish a more realistic analytical equation for the buckling coefficient $\mathrm{k}_{\mathrm{cr}}$.

\subsubsection{New equations for the buckling coefficient $k_{c r}$}

A parametric study is conducted to determine the influence of the parameters $\beta, a / h_{w}$ and $s_{s} / h_{w}$. An analytical equation is then derived by regression analysis to calculate the buckling coefficient of a web panel which is subjected to opposite patch loading, considering the real conditions at the panel edges.

Two formulae are proposed (Eqs. (6.a) and (6.b)) for the calculation of the buckling critical coefficient depending on the aspect ratio of the web panel. It can be observed that when $\beta$ is close to zero, the web panel behaves as a simply supported panel and when $\beta$ is high it does as a plate with clamped edges. As for the influence of the loading length factor $\mathrm{s}_{\mathrm{s}} / \mathrm{h}_{\mathrm{w}}$ it was already considered in the calculation of the buckling coefficients $\mathrm{k}_{\mathrm{crs}}$ and $\mathrm{k}_{\mathrm{crf}}$ defined by Eqs. (4) and (5), respectively. Finally, it remains to account for the influence of the aspect ratio $\mathrm{a} / \mathrm{h}_{\mathrm{w}}$ to calculate the buckling coefficient $\mathrm{k}_{\mathrm{cr}}$ of the web panel:

- For $1.0 \leq \mathrm{a} / \mathrm{h}_{\mathrm{w}} \leq 1.1$

$$
\mathrm{k}_{\mathrm{cr}}=\left(\mathrm{k}_{\mathrm{crs}}+\mathrm{k}_{\mathrm{crf}} \lambda \beta\right) /(1+\beta)
$$

with

$$
\begin{aligned}
& \lambda=0.178\left(\mathrm{a} / \mathrm{h}_{\mathrm{w}}\right)^{2}-1.139\left(\mathrm{a} / \mathrm{h}_{\mathrm{w}}\right)+2.541 \quad 1 \leq \beta \leq 1.34 \\
& \lambda=0.148\left(\mathrm{a} / \mathrm{h}_{\mathrm{w}}\right)^{2}-0.950\left(\mathrm{a} / \mathrm{h}_{\mathrm{w}}\right)+2.118 \quad 1.34<\beta \leq 128
\end{aligned}
$$

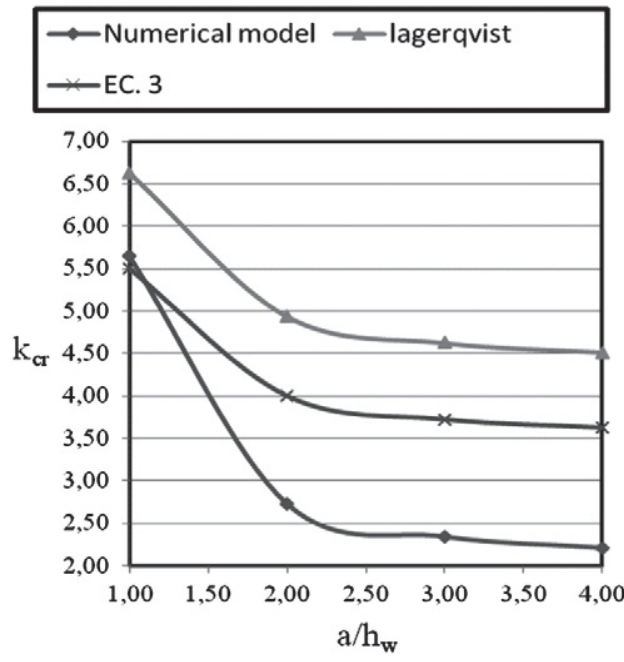

(a) $\beta=1$ and $\mathrm{s}_{\mathrm{s}} / \mathrm{h}_{\mathrm{w}}=0.5$

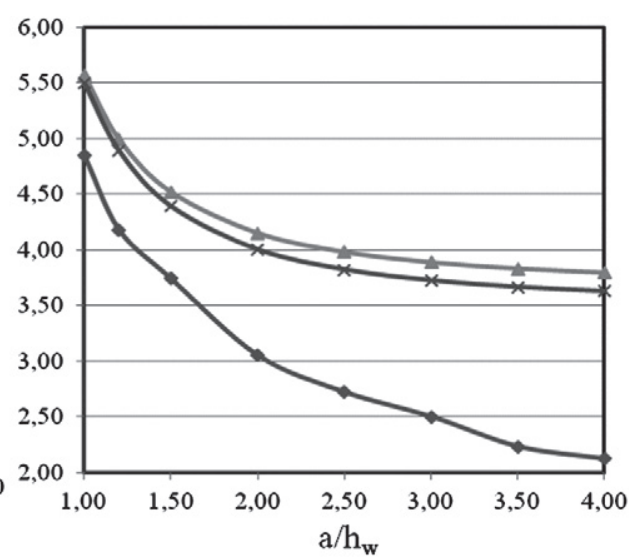

(b) $\beta=1$ and $\mathrm{s}_{\mathrm{s}} / \mathrm{h}_{\mathrm{w}}=0.1$

Fig. 9. Buckling coefficient $k_{c r}$ versus the aspect ratios $a / h_{w}$. 


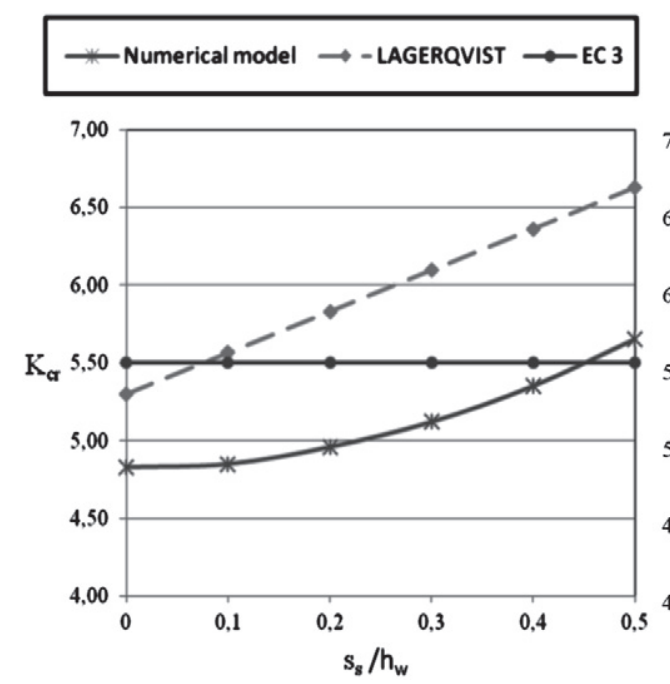

(a) $\beta=3.91$ and $\mathrm{a} / \mathrm{h}_{\mathrm{w}}=1$

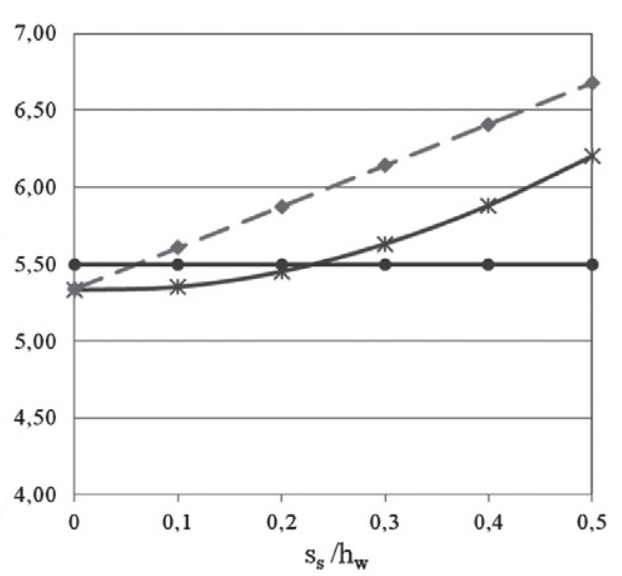

(b) $\beta=1$ and $\mathrm{a} / \mathrm{h}_{\mathrm{w}}=1$

Fig. 10. Buckling coefficient $k_{c r}$ versus the coefficient $s_{s} / h_{w}$.

- For $1.1<\mathrm{a} / \mathrm{h}_{\mathrm{w}} \leq 4.0$

$\mathrm{k}_{\mathrm{cr}}=\left(\mathrm{k}_{\mathrm{crs}}+\mathrm{k}_{\mathrm{crf}} \psi \beta\right) /(1+\psi \beta)$

and

$$
\begin{array}{ll}
\psi=0.086\left(\mathrm{a} / \mathrm{h}_{\mathrm{w}}\right)^{2}-0.550\left(\mathrm{a} / \mathrm{h}_{\mathrm{w}}\right)+1.225 & 1 \leq \beta \leq 3.91 \\
\psi=0.380\left(\mathrm{a} / \mathrm{h}_{\mathrm{w}}\right)^{2}-2.437\left(\mathrm{a} / \mathrm{h}_{\mathrm{w}}\right)+5.436 & 3.91<\beta \leq 128
\end{array}
$$

The factors $\lambda$ and $\psi$ represent the influence of the aspect ratio of the web panel on the buckling coefficient $\mathrm{k}_{\mathrm{cr}}$. The parameter $\mathrm{k}_{\mathrm{crs}}$ is the buckling coefficient for a simply supported plate with opposite patch loading which is calculated according to Eq. (4). The parameter $\mathrm{k}_{\mathrm{crf}}$ is the buckling coefficient of a panel with clamped supports at the loaded edges and simple supports at the two other edges. This coefficient is given by Eq. (5).

The buckling coefficients of a web panel which were obtained for various values of $\left(\mathrm{a} / \mathrm{h}_{\mathrm{w}}\right), \mathrm{s}_{\mathrm{s}}$ and $\beta$ by means of the numerical model and Eqs. (6.a) and (6.b) are given in Table 2. In this Table, the difference (error) between the results of the numerical model and those of Eqs. (2), (3) and (6.a) and (6.b) is also reported. It can be noted that Eq. (2), proposed by Lagerqvist, and Eq. (3) proposed in the Eurocode 3 estimate $\mathrm{k}_{\mathrm{cr}}$ with differences of $51 \%$ and $42 \%$, respectively. However, Eqs. (6.a) and (6.b) estimate $\mathrm{k}_{\mathrm{cr}}$ with an error of $10 \%$ only, which reflects a reasonable accuracy considering the simplicity of the equation with regard to the complexity of the problem.

Table 2

\begin{tabular}{|c|c|c|c|c|c|c|c|c|c|c|c|c|c|c|c|c|}
\hline \multirow{3}{*}{\multicolumn{2}{|c|}{$\begin{array}{l}\mathrm{h}_{\mathrm{w}}=1000 \\
\mathrm{t}_{\mathrm{w}}=4 \\
\mathrm{~b}_{\mathrm{f}}=250\end{array}$}} & \multirow{3}{*}{\multicolumn{3}{|c|}{ FEM (CAST3M) }} & \multirow{3}{*}{\multicolumn{3}{|c|}{ Eqs. (6.a) and (6.b) }} & \multicolumn{9}{|c|}{ Deviation (\%) } \\
\hline & & & & & & & & \multicolumn{3}{|c|}{$\left(\mathrm{k}_{\mathrm{FEM}}{ }^{\mathrm{a}}-\mathrm{k}_{6}\right) / \mathrm{k}_{6}{ }^{\mathrm{b}}$} & \multicolumn{3}{|c|}{$\left(\mathrm{k}_{\mathrm{FEM}}-\mathrm{k}_{\text {lager }}\right) / \mathrm{k}_{\text {lager }}{ }^{\mathrm{c}}$} & \multicolumn{3}{|c|}{$\left(\mathrm{k}_{\mathrm{FEM}}-\mathrm{k}_{\mathrm{EC} 3}\right) / \mathrm{k}_{\mathrm{EC} 3}{ }^{\mathrm{d}}$} \\
\hline & & & & & & & & \multicolumn{3}{|c|}{ FEM and Eqs. (6.a) and (6.b) } & \multicolumn{3}{|c|}{ FEM and model of Lagerqvist } & \multicolumn{3}{|c|}{ FEM and model of EC3 } \\
\hline \multirow[t]{2}{*}{$\mathrm{s}_{\mathrm{s}}$} & \multirow[t]{2}{*}{$\beta$} & \multicolumn{3}{|l|}{$\mathrm{a} / \mathrm{h}_{\mathrm{w}}$} & \multicolumn{3}{|l|}{$\mathrm{a} / \mathrm{h}_{\mathrm{w}}$} & \multicolumn{3}{|l|}{$\mathrm{a} / \mathrm{h}_{\mathrm{w}}$} & \multicolumn{3}{|l|}{$\mathrm{a} / \mathrm{h}_{\mathrm{w}}$} & \multicolumn{3}{|l|}{$\mathrm{a} / \mathrm{h}_{\mathrm{w}}$} \\
\hline & & 1 & 2 & 4 & 1 & 2 & 4 & 1 & 2 & 4 & 1 & 2 & 4 & 1 & 2 & 4 \\
\hline \multirow[t]{5}{*}{0.0} & 1 & 4.83 & 2.57 & 2.11 & 4.92 & 2.37 & 2.07 & 1.95 & -7.61 & -1.73 & -8.87 & -34.94 & -41.59 & -12.18 & -35.75 & -41.79 \\
\hline & 3.91 & 5.33 & 3.55 & 2.91 & 5.36 & 3.22 & 2.95 & 0.60 & -9.37 & 1.29 & -0.20 & -11.04 & -20.34 & -3.09 & -11.25 & -19.72 \\
\hline & 16.00 & 5.55 & 4.13 & 3.83 & 5.87 & 4.05 & 3.91 & 5.84 & -1.94 & 2.07 & 2.78 & 1.98 & 3.16 & 0.91 & 3.25 & 5.66 \\
\hline & 54 & 5.71 & 4.33 & 4.24 & 6.02 & 4.10 & 3.97 & 5.39 & -5.26 & -6.29 & 4.37 & 5.07 & 12.06 & 3.82 & 8.25 & 16.97 \\
\hline & 128 & 5.84 & 4.41 & 4.39 & 6.05 & 4.12 & 3.99 & 3.67 & -6.68 & -9.12 & 5.49 & 5.34 & 14.06 & 6.18 & 10.25 & 21.10 \\
\hline \multirow[t]{5}{*}{0.2} & 6.35 & 4.96 & 2.60 & 2.13 & 5.01 & 2.42 & 2.12 & 0.96 & -6.80 & -0.45 & -14.92 & -40.16 & -46.40 & -9.82 & -35.00 & -41.24 \\
\hline & 10.00 & 5.45 & 3.58 & 2.94 & 5.46 & 3.28 & 3.01 & 0.14 & -8.28 & 2.45 & -7.23 & -18.44 & -26.84 & -0.91 & -10.50 & -18.90 \\
\hline & 16.00 & 5.66 & 4.17 & 3.86 & 5.98 & 4.13 & 3.99 & 5.68 & -0.87 & 3.44 & -4.72 & -6.40 & -5.48 & 2.91 & 4.25 & 6.48 \\
\hline & 24.00 & 5.79 & 4.36 & 4.27 & 6.13 & 4.19 & 4.06 & 5.84 & -3.97 & -4.96 & -3.79 & -3.82 & 2.60 & 5.27 & 9.00 & 17.79 \\
\hline & 32.00 & 5.91 & 4.43 & 4.42 & 6.17 & 4.20 & 4.07 & 4.33 & -5.18 & -7.82 & -2.95 & -3.80 & 4.40 & 7.45 & 10.75 & 21.93 \\
\hline \multirow[t]{5}{*}{0.5} & 6.35 & 5.65 & 2.73 & 2.21 & 5.44 & 2.68 & 2.37 & -3.65 & -1.86 & 7.09 & -14.71 & -44.71 & -51.06 & 2.73 & -31.75 & -39.03 \\
\hline & 10.00 & 6.20 & 3.79 & 3.07 & 5.96 & 3.63 & 3.35 & -3.87 & -4.18 & 9.10 & -7.13 & -24.02 & -32.77 & 12.73 & -5.25 & -15.31 \\
\hline & 16.00 & 6.41 & 4.42 & 4.07 & 6.55 & 4.57 & 4.43 & 2.11 & 3.46 & 8.86 & -5.04 & -12.69 & -12.30 & 16.55 & 10.50 & 12.28 \\
\hline & 24.00 & 6.51 & 4.61 & 4.52 & 6.71 & 4.63 & 4.50 & 3.06 & 0.47 & -0.39 & -4.81 & -10.51 & -4.43 & 18.36 & 15.25 & 24.69 \\
\hline & 32.00 & 6.60 & 4.68 & 4.66 & 6.75 & 4.65 & 4.52 & 2.29 & -0.71 & -2.99 & -4.63 & -10.57 & -3.14 & 20.00 & 17.00 & 28.55 \\
\hline
\end{tabular}

Comparison between the buckling coefficients obtained using FEM and the equations of the other authors.

a Obtained from finite element model.

b Eqs. (6.a) and (6.b).

c Equation of Lagerqvist.

d Equation of Eurocode 3 part 1-5. 


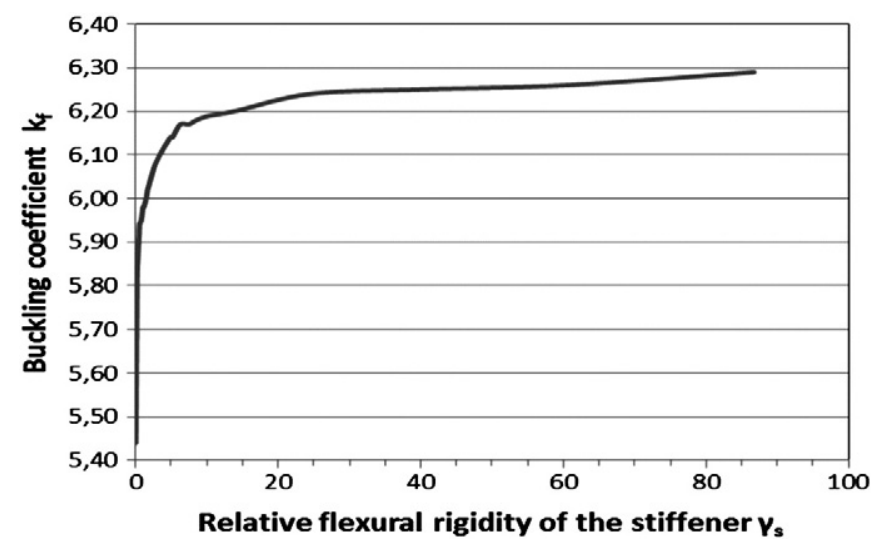

Fig. 11. Influence of the relative flexural rigidity $\gamma_{\mathrm{s}}$ of the stiffener on $\mathrm{k}_{\mathrm{f}}$ for girder.

\subsection{Case of longitudinally stiffened web panel}

In this part, the influence of a longitudinal stiffener on the buckling coefficient $\mathrm{k}_{\mathrm{f}}$ is analyzed for a web panel that is subjected to opposite patch loading. The web panel is stiffened by an asymmetric open section stiffener (Fig. 4).

\subsubsection{Parametric study}

The web panel numerical model, described in the preceding sections, is considered now with the same boundary conditions and a longitudinal stiffener added. The stiffener is modeled according to the geometry presented in Fig. 4 with dimensions $\mathrm{h}_{\mathrm{w}}=1000 \mathrm{~mm}, \mathrm{a}=1000,2000$ and $4000 \mathrm{~mm}$ and $\mathrm{t}_{\mathrm{w}}=4 \mathrm{~mm}$.

The degrees of freedom 1, 5 and 6 are fixed at the end cross sections of the stiffener. The evolution of the buckling coefficient $\mathrm{k}_{\mathrm{f}}$ as a function of the bending stiffness of the stiffener $\gamma_{s}$ is shown in Fig. 11 for fixed values of $b_{1} / h_{w}=0.2, s_{s} / h_{w}=0.3, a / h_{w}=1$ and $\beta=2$. The dimension $b_{1}$ is the height of the upper sub-panel (Fig. 4). It can be seen that the buckling coefficient $\mathrm{k}_{\mathrm{f}}$ increases with $\gamma_{\mathrm{s}}$ and reaches a plateau corresponding to the limit buckling mode with double waves along the height of the web, due to the prevention of out of plane displacements at the stiffener position (Fig. 12).

The torsional rigidity of open section stiffeners is being generally negligible and the study will be restricted to the influence of their relative bending stiffness.

Fig. 13 shows the variations of the buckling coefficient $\mathrm{k}_{\mathrm{f}}$ versus the parameter $b_{1} / h_{w}$ for $a / h_{w}=1,2$ and $4, s_{s} / h_{w}=0,0.3$ and 0.5 and $\beta=2$. It is noted that among all the considered parameter combinations, the maximum buckling coefficient is reached when the stiffener is placed at mid-height of the panel (i.e., $b_{1}=h_{w} / 2$ ).

The evolution of the buckling coefficient $\mathrm{k}_{\mathrm{f}}$ versus the relative bending stiffness $\gamma_{s}$ is presented in Fig. 14 for $\mathrm{a} / \mathrm{h}_{\mathrm{w}}=1,2$ and 4 , for $\mathrm{b}_{1} / \mathrm{h}_{\mathrm{w}}=0.5, \mathrm{~s}_{\mathrm{s}} / \mathrm{h}_{\mathrm{w}}=0.3$ and $\beta=2$. It shows that the buckling coefficient increases quickly and then stabilizes from a certain value defined as the optimal flexural rigidity $\gamma^{\mathrm{t}}$. It is also noted from the plots that this optimal flexural stiffness increases with the web panel length.

In Fig. 15, the evolution of $\mathrm{k}_{\mathrm{f}}$ versus $\gamma_{\mathrm{s}}$ is shown for the two aspect ratios $\mathrm{a} / \mathrm{h}_{\mathrm{w}}=1$ and 4 of the panel, the loading lengths: $\mathrm{s}_{\mathrm{s}} / \mathrm{h}_{\mathrm{w}}=0,0.3$ and $0.5, \beta=2$, and $b_{1} / h_{w}=0.5$. These results show that, for a fixed aspect ratio, the loading length has no influence on the optimal flexural stiffness $\gamma^{\mathrm{t}}$.

Finally, the evolution of $\mathrm{k}_{\mathrm{f}}$ versus $\gamma_{\mathrm{s}}$ is presented in Fig. 16 for different positions of the stiffener $\left(0.3 \leq b_{1} / h_{w} \leq 0.5\right)$ and two values of the aspect ratio $\left(\mathrm{a} / \mathrm{h}_{\mathrm{w}}=1\right.$ and 4$)$. It can be seen that for $\mathrm{a} / \mathrm{h}_{\mathrm{w}}=1$ and $b_{1}$ between $0.3 h_{w}$ and $0.5 h_{w}$ the optimal stiffness $\gamma^{t}$ can be clearly identified. However, this value is difficult to identify when $\mathrm{a} / \mathrm{h}_{\mathrm{w}}=4$ because the smoothness of the curve and the decrease of $b_{1} / h_{w}$ after a maximum is reached. Therefore, a bilinear model is chosen to approximate the evolution of the buckling coefficient $\mathrm{k}_{\mathrm{f}}$

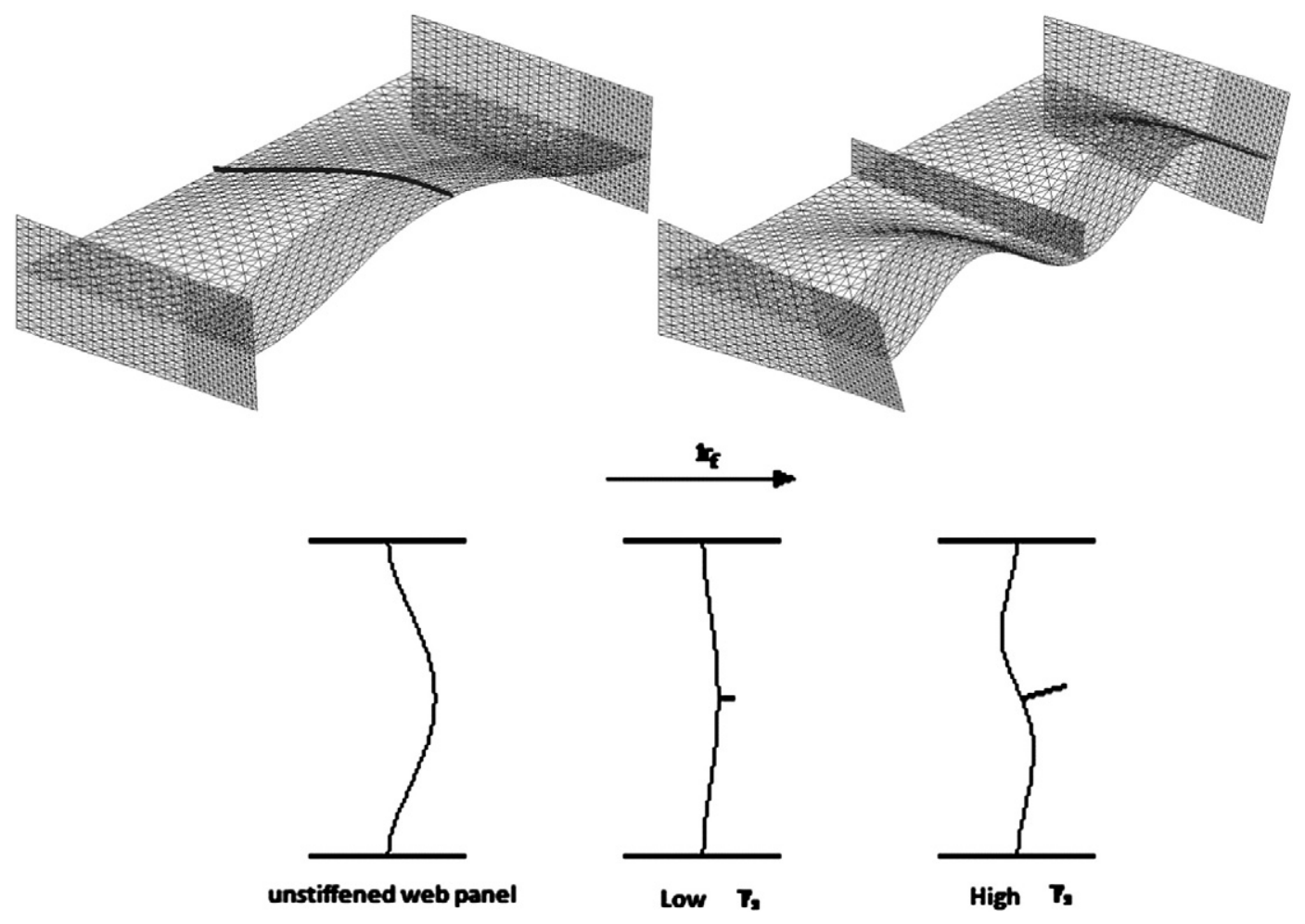

Fig. 12. Evolution of the instability mode versus $\gamma_{\mathrm{s}}$. 


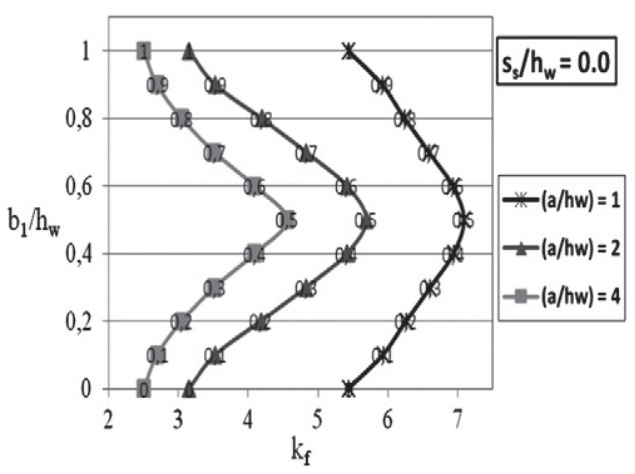

(a) $: \mathrm{s}_{\mathrm{s}} / \mathrm{h}_{\mathrm{w}}=0.0$

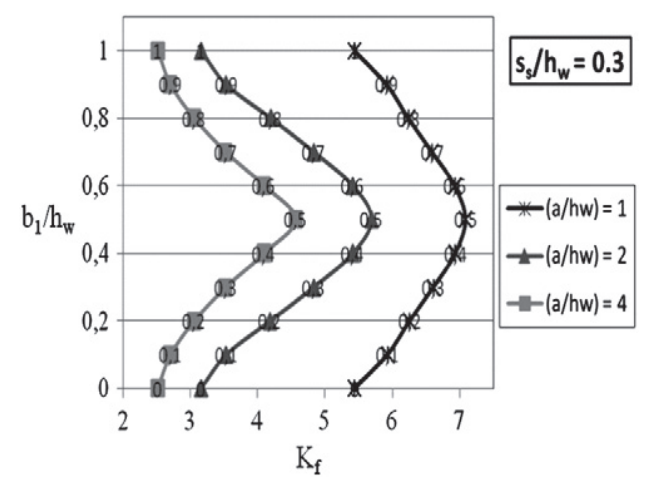

(b) $: \mathrm{s}_{\mathrm{s}} / \mathrm{h}_{\mathrm{w}}=0.3$

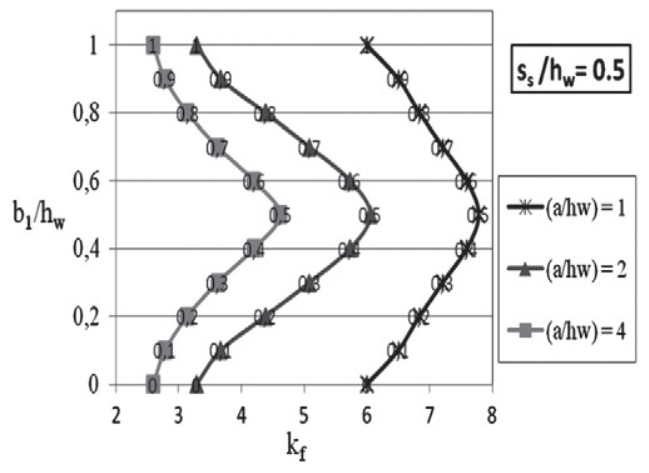

(c) : $\mathrm{s}_{\mathrm{s}} / \mathrm{h}_{\mathrm{w}}=0.5$

Fig. 13. Buckling coefficient $k_{f}$ versus $b_{1} / h_{w}$ for various aspect ratios. Effect of the $\left(s_{s} / h_{w}\right)$ ratio.

(Fig. 16). The first line increases quickly for $\gamma_{s} \leq \gamma^{t}$ and the second line describes the slow increase when $\gamma_{s}>\gamma^{t}$. The optimal rigidity $\gamma^{t}$ is then determined from the intersection of the two lines (Fig. 17). The values of the optimal rigidity are given in Table 3 for different values of the aspect ratio.

From this study an empirical model is obtained. Table 3 shows that the optimal rigidity is mainly influenced by the aspect ratio of the loaded panel $\left(b_{1} / h_{w}\right)$. A parametric study is conducted with $a / h_{w}=$ 1 to 4 and $b_{1} / h_{w}=0.3$ to 0.5 . Finally, by applying a linear regression to the results of 30 cases, Eq. (7) is proposed to calculate the optimal rigidity of the stiffener.

$\gamma^{\mathrm{t}}=3.37\left(\mathrm{a} / \mathrm{h}_{\mathrm{w}}\right)^{2.08}+0.4\left(\mathrm{~b}_{1} / \mathrm{a}\right)^{-1.92}$

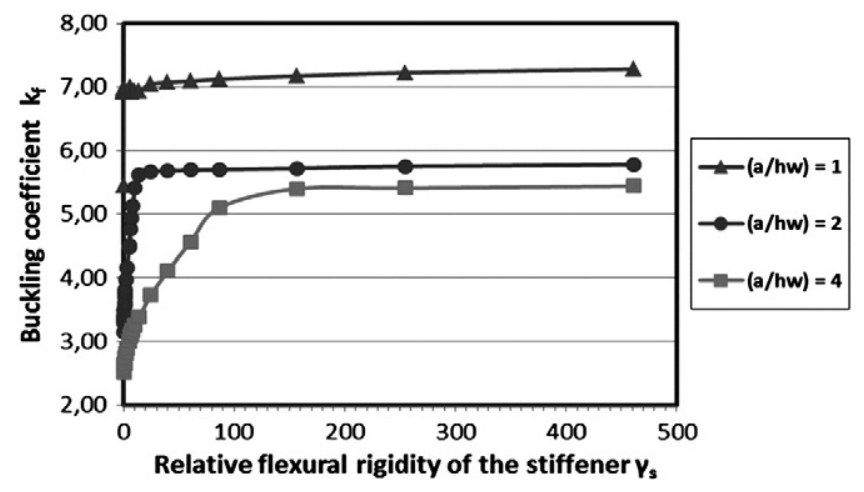

Fig. 14. Buckling coefficient $k_{f}$ versus $\gamma_{s}$ for various aspect ratios.
4.4.2. Analytical value of the buckling coefficient $k_{f}$

The addition of a longitudinal stiffener creates a higher order mode and therefore an increase in the panel resistance. The simple Eq. (8) is proposed to evaluate the buckling coefficient $\mathrm{k}_{\mathrm{f}}$ of the longitudinally stiffened web panel, which is subjected to opposite patch loading.

$\mathrm{k}_{\mathrm{f}}=\mathrm{k}_{\mathrm{cr}}+\mathrm{k}_{\mathrm{st}}$.

Here, $\mathrm{k}_{\mathrm{cr}}$ is the buckling coefficient of an unstiffened web panel, resulting from Eqs. (6.a) and (6.b). The parameter $\mathrm{k}_{\mathrm{st}}$ represents the contribution of the longitudinal stiffener to the buckling resistance of the panel additive.

From the study of longitudinally stiffened web panel, it follows that the buckling coefficient $\mathrm{k}_{\mathrm{st}}$ depends on the relative flexural stiffness $\gamma_{s}$ of the longitudinal stiffener and the aspect ratio of the loaded panel $\left(b_{1} / a\right)$. A parametric study is therefore established to assess the influence of the parameters $\gamma_{\mathrm{s}}, \mathrm{a} / \mathrm{h}_{\mathrm{w}}$ and $\mathrm{b}_{1} / \mathrm{a}$ on $\mathrm{k}_{\mathrm{st}}$. The analysis, carried out for the following intervals: $\gamma_{\mathrm{s}}=0.19$ to $461, \mathrm{a} / \mathrm{h}_{\mathrm{w}}=1$ to 4 and $b_{1} / a=0.075$ to 0.5 , led to the empirical model (Eqs. (9-a) and (9-b)) for calculating the buckling coefficient $\mathrm{k}_{\mathrm{st}}$.

- For $0 \leq \gamma_{s} \leq \gamma^{t}$

$$
\mathrm{k}_{\mathrm{st}}=\left(\gamma_{\mathrm{s}} / 20\right)+2.45\left(\mathrm{~b}_{1} / \mathrm{a}\right)+\left(\gamma_{\mathrm{s}} / 50\right)\left(\mathrm{b}_{1} / \mathrm{a}\right)-0.06
$$

- For $\gamma_{s}>\gamma^{t}$

$$
\mathrm{k}_{\mathrm{st}}=\left(\gamma_{\mathrm{s}} / 250\right)+0.29\left(\mathrm{~b}_{1} / \mathrm{a}\right)-\left(\gamma_{\mathrm{s}} / 125\right)\left(\mathrm{b}_{1} / \mathrm{a}\right)+1.391 \text {. }
$$

Table 4 reports the deviation between the values of the buckling coefficient $\mathrm{k}_{\mathrm{f}}$ which was calculated by using the numerical model 


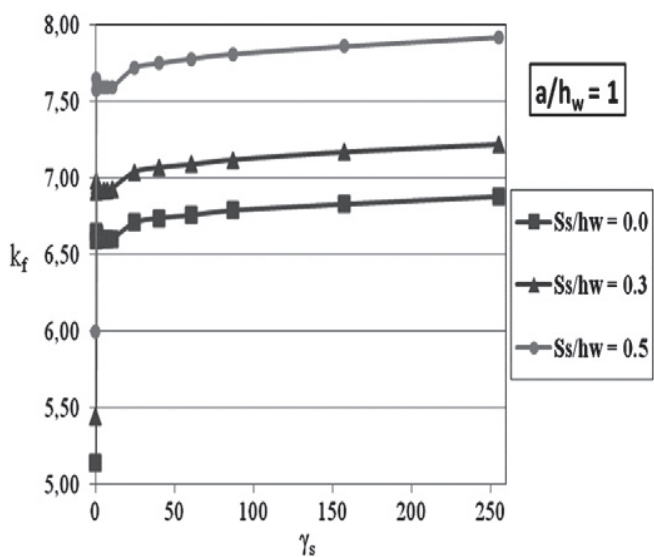

(a) $: \mathrm{a} / \mathrm{h}_{\mathrm{w}}=1$

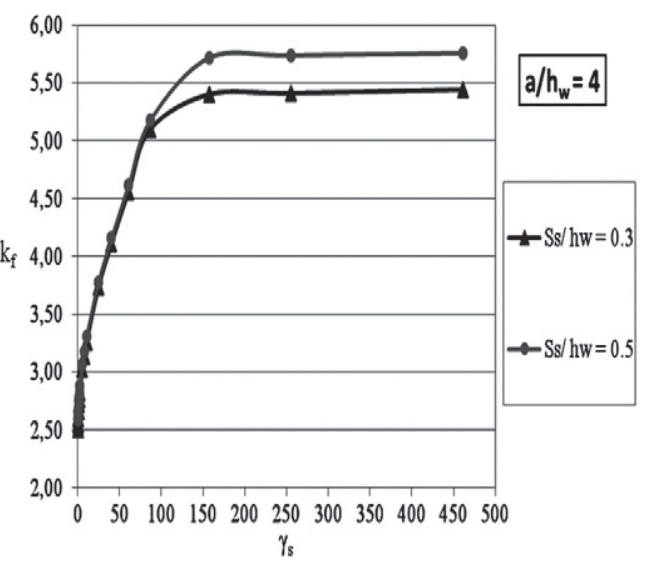

(b) $: \mathrm{a} / \mathrm{h}_{\mathrm{w}}=4$

Fig. 15. Buckling coefficient $k_{f}$ versus $\gamma_{s}$ for various $s_{s} / h_{w}$ ratios.

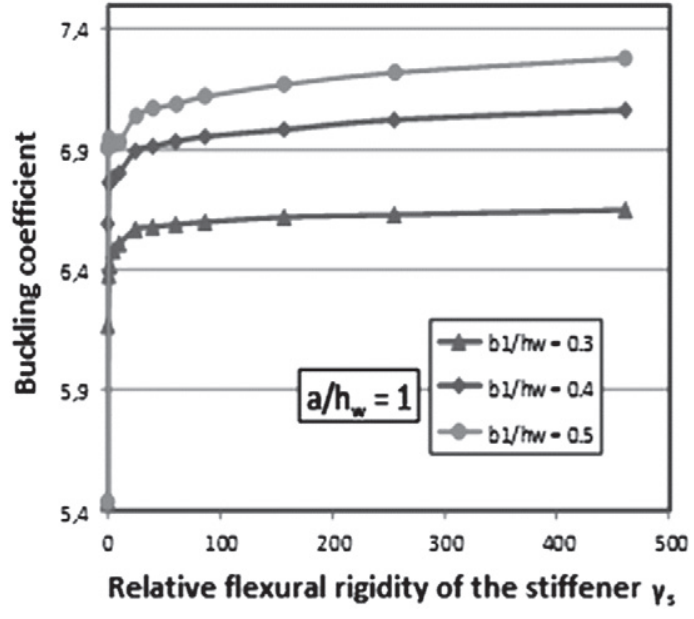

(a) $: \mathrm{a} / \mathrm{h}_{\mathrm{w}}=1$

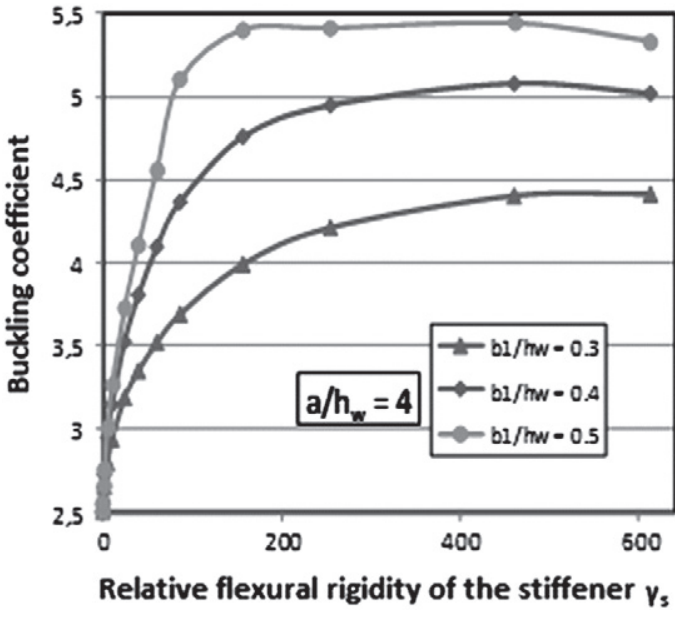

(b) $: \mathrm{a} / \mathrm{h}_{\mathrm{w}}=4$

Fig. 16. Buckling coefficient $k_{f}$ versus $\gamma_{s}$ for various $b_{1} / h_{w}$ ratios.

and the analytical model (Eq. (8)). It shows that the coefficient $\mathrm{k}_{\mathrm{f}}$ is analytically with a maximum error of $14 \%$ in comparison with the numerical model. This error can be considered as acceptable for an

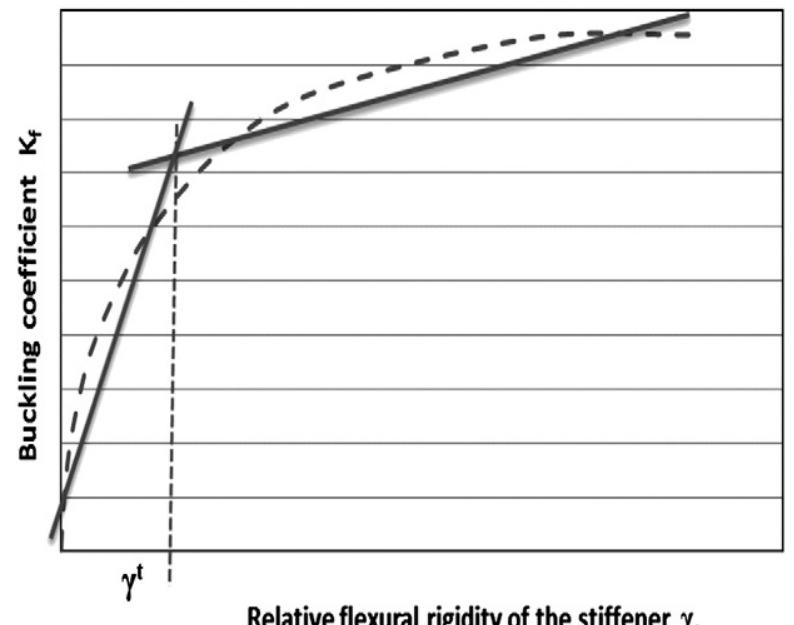

Fig. 17. Determination of transition rigidities $\gamma^{\mathrm{t}}$. analytical model that is general enough to account for the complex phenomena of buckling while covering a wide range of cases.

\section{Conclusion}

The present study addresses the buckling of the I beam web panels which are subjected to opposite patch loading considering the restraints due to the flanges in a more realistic way than proposed by the European codes. A numerical model is developed and its results are exploited to derive an empirical analytical equation for the buckling

Table 3

Transition rigidity $\gamma^{t}$ for various values of the relative position of the stiffener

\begin{tabular}{llr}
\hline $\mathrm{a} / \mathrm{h}_{\mathrm{w}}$ & $\mathrm{b}_{1} / \mathrm{h}_{\mathrm{w}}$ & $\gamma^{\mathrm{t}}$ \\
\hline 1 & 0.3 & 8 \\
& 0.4 & 6 \\
& 0.5 & 5 \\
2 & 0.3 & 34 \\
& 0.4 & 21 \\
& 0.5 & 19 \\
4 & 0.3 & 113 \\
& 0.4 & 98 \\
& 0.5 & 80 \\
\hline
\end{tabular}


Table 4

Comparison of buckling coefficient $\mathrm{k}_{\mathrm{FEM}}$ obtained from the FEM and Eq. (8).

\begin{tabular}{|c|c|c|c|c|c|}
\hline \multirow[t]{3}{*}{$\mathrm{a} / \mathrm{h}_{\mathrm{w}}$} & \multirow[t]{3}{*}{$\gamma_{\mathrm{s}}$} & & \multicolumn{3}{|c|}{$\mathrm{b}_{1} / \mathrm{h}_{\mathrm{w}}$} \\
\hline & & & 0.3 & 0.4 & 0.5 \\
\hline & & & \multicolumn{3}{|c|}{$\left(\mathrm{k}_{\mathrm{FEM}}-\mathrm{k}_{8}^{\mathrm{b}}\right) / \overline{\mathrm{kFEM}}^{\mathrm{a}}(\%)$} \\
\hline \multirow[t]{12}{*}{1} & \multirow{4}{*}{$\gamma_{s} \leq \gamma^{t}$} & 0.19 & 7 & 9 & 10 \\
\hline & & 1.01 & 9 & 11 & 10 \\
\hline & & 1.85 & 9 & 10 & 9 \\
\hline & & 5.17 & 7 & 7 & 5 \\
\hline & \multirow[t]{8}{*}{$\gamma_{s}>\gamma^{t}$} & 10.33 & 1 & 3 & 4 \\
\hline & & 24.62 & 1 & 4 & 6 \\
\hline & & 40.17 & 1 & 4 & 7 \\
\hline & & 60.70 & 1 & 4 & 7 \\
\hline & & 86.75 & 2 & 4 & 7 \\
\hline & & 157.25 & 3 & 4 & 8 \\
\hline & & 255.22 & 5 & 3 & 9 \\
\hline & & 460.88 & 9 & 1 & 10 \\
\hline \multirow[t]{12}{*}{2} & \multirow[t]{6}{*}{$\gamma_{s} \leq \gamma^{t}$} & 0.19 & 0 & 3 & 6 \\
\hline & & 1.01 & 3 & 3 & 1 \\
\hline & & 1.85 & 5 & 7 & 6 \\
\hline & & 5.17 & 8 & 14 & 14 \\
\hline & & 10.33 & 8 & 11 & 13 \\
\hline & & 24.62 & 1 & 13 & 14 \\
\hline & \multirow[t]{6}{*}{$\gamma_{s}>\gamma^{t}$} & 40.17 & 6 & 13 & 14 \\
\hline & & 60.70 & 7 & 12 & 13 \\
\hline & & 86.75 & 6 & 10 & 13 \\
\hline & & 157.25 & 3 & 11 & 12 \\
\hline & & 255.22 & 2 & 10 & 11 \\
\hline & & 460.88 & 11 & 1 & 9 \\
\hline \multirow[t]{11}{*}{4} & \multirow[t]{8}{*}{$\gamma_{s} \leq \gamma^{t}$} & 0.19 & 8 & 10 & 12 \\
\hline & & 1.01 & 7 & 8 & 9 \\
\hline & & 1.85 & 7 & 6 & 7 \\
\hline & & 5.17 & 7 & 4 & 4 \\
\hline & & 10.33 & 10 & 6 & 4 \\
\hline & & 24.62 & 14 & 13 & 9 \\
\hline & & 60.70 & 12 & 13 & 14 \\
\hline & & 86.75 & 13 & 13 & 12 \\
\hline & \multirow{3}{*}{$\gamma_{s}>\gamma^{t}$} & 157.25 & 11 & 5 & 11 \\
\hline & & 255.22 & 12 & 2 & 12 \\
\hline & & 460.88 & 12 & 8 & 0 \\
\hline
\end{tabular}

a Obtained from finite element model.

b Eq. (8).

critical coefficient of the beam web panel. The rotational rigidity provided by the flanges on web panel edges is accurately accounted for in this new equation. The approach is extended to the case of a web panel which was reinforced with a longitudinal stiffener and was subjected to opposite patch loading. By using the results of the numerical model, the optimal position and rigidity of the stiffener are identified. The contribution of the stiffener to the buckling resistance of the panel is determined and a general analytical model is proposed to estimate the buckling critical coefficient $\mathrm{k}_{\mathrm{f}}$ of a stiffened web panel which is subjected to opposite patch loading.
In a future work, this study is to be extended by performing elasticplastic finite element analyses and carrying out validation experiments on web panels that would be subjected to opposite patch loading with and without stiffeners.

\section{References}

[1] Pasquet P. User manual - finite element software package Cast3m. Saclay: CEA; 1998 [in French, English information on web site]

[2] Sommerfield A. Uber die Knicksicherheit der Stege walzwerprofielen. Seitf Math U Phys 1906;5(4):113.

[3] Timoshenko SP. Buckling of thin plates under compressive and shearing stresses, Stephen Timoshenko Papers (SC0641). Department of Special Collections and University Archives. Stanford, California: Stanford University Libraries; 1907.

[4] Timoshenko SP, Gere JM. Theory of elastic stability. Second ed. Mc-Graw Hill; 1986.

[5] Legget DMA. The effect of two isolated forces on the elastic stability of a flat rectangular plate, vol. 33. Proceedings, Cambridge Philosophical Society: 1937. p. 325-39.

[6] Yamaki N. Buckling of a rectangular plate under locally distributed forces applied on the two opposite edges. Report of the Institute of High Speed Mechanics, vol. 34. Japan: Tohoku University; 1954. p. 55-71.

[7] Leissa W, Ayoub EF. Vibration and buckling of a simply supported rectangular plate subjected to a pair of in-plane concentrated forces. J Sound Vib 1988;127: 155-77.

[8] Deolasi PJ, Datta PK. Parametric instability characteristics of rectangular plates subjected to localised edge loading (compression \& tension). Comput Struct 1993;54(1):73-82.

[9] Khan MZ, Walker AC. Buckling of plates subjected to localized edge loading. Struct Eng June, 1972;50(6):225-32.

[10] Protte W. Beulwerte fur Rechteckplatten unter Belastung beider Längsränder, Stahlbau, Heft 7, vol. 62; 1993. p. 189-94.

[11] Lagerqvist 0 . Patch loading. Resistance of steel girders subjected to concentrated forces, Division of Steel Structures, Lulea University of Technology, Sweden, Doctoral thesis, 1994.

[12] Alfutov NA, Balabukh LI. Energy criterion of the stability of elastic bodies which does not require the determination of the initial stress-strain state. Appl Math Mech 1968;32(4):726-31.

[13] Khan MZ, Johns KC. Buckling of web plates under combined loadings. J Struct Div ASCE 1975;101(10):2079-92.

[14] Robert TM, Shahabian F. Buckling of slender web plates subjected to combinations of in-plane loading. J Constr Steel Res 1999;51:99-121.

[15] Ren T, Tong G. Elastic buckling of web plates in I-girders under patch and wheel loading. J Eng Struct 2005;27:1528-36.

[16] EN-1993-1-5. Eurocode 3 - design of steel structures - part 1-5: general rules: plated structural elements. CEN; 2006.

[17] Graves Smith TR, Gierlinski JT. Buckling of stiffened webs by local edge loads. J Struct Eng 1982;47:1357-66.

[18] Skaloud M. Optimum rigidity of stiffeners of webs and flanges. London and New York: Applied Science Publishers; 1983.

[19] Graciano C. Patch loading: Resistance of longitudinally stiffened steel girder webs, Doctoral thesis, Lulea University, Sweden, 2001.

[20] Klöppel K, Scheer J. Beulwerte ausgesteifter Rechteckplatten (band I). Berlin: W. Ernst and Sohn; 1960.

[21] Klöppel K, Möller KH. Beulwerte ausgesteifter Rechteckplatten (band II). BerlinMünchen: W. Ernst and Sohn; 1968.

[22] ECCS, European recommendations for the design of longitudinally stiffened webs and of stiffened compression flanges. Technical committee 8,60. Technical working group 8-3, First ed.; 1990. 